\title{
Stressful Life Events Among Children Aged 5-17 Years by Disability Status: United States, 2019
}

\author{
Heidi Ullmann, Ph.D., Julie D. Weeks, Ph.D., and Jennifer H. Madans, Ph.D.
}

\section{Key findings}

\section{Data from the National Health Interview Survey}

- In $2019,17.2 \%$ of children with disability had been exposed to violence in their neighborhood compared with $5.3 \%$ of children without disability.

- The percentage of children aged 5-17 years who had lived with a parent or guardian who served time in jail or prison was higher for children with disability.

- Among children aged 5-17 years, $21.6 \%$ of those with disability and $7.5 \%$ of those without disability had lived with someone who was mentally ill or severely depressed.

- In $2019,17.6 \%$ of children with disability had lived with someone with an alcohol or drug problem, compared with $8.6 \%$ of children without disability.

- The percentage of children who had experienced two or more of the four stressful life events was higher among those with disability.
Children with disabilities are at increased risk of experiencing stressful life events $(1,2)$. These events include various forms of abuse, neglect, and household instability, such as exposure to violence, parental or guardian incarceration, and living with someone with mental illness or alcohol or drug problems (3). Stressful life events experienced in childhood may have lifelong effects on physical and mental health outcomes (4-11), as well as socioeconomic outcomes, including educational attainment and employment (12). This report presents disparities in four stressful life events among children aged 5-17 years by disability status using 2019 National Health Interview Survey (NHIS) data.

\section{The percentage of children who experienced neighborhood violence or parental incarceration was higher among children with disability than children without disability.}

Figure 1. Percentage of children aged 5-17 years who had been exposed to violence in their neighborhood, or who lived with a parent or guardian who had been incarcerated, by disability status: United States, 2019

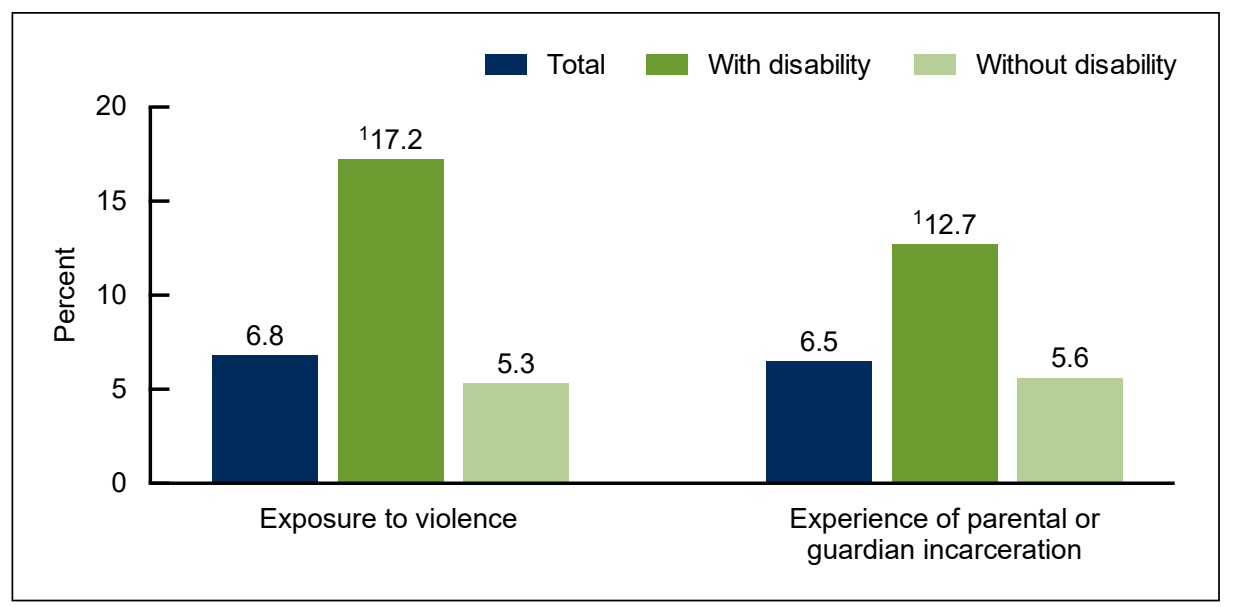

${ }^{1}$ Significantly different from children without disability $(p<0.05)$.

NOTES: Violence exposure is based on responses by a knowledgeable adult, usually a parent, to the survey question, "Has (child) ever been the victim of violence or witnessed violence in his/her neighborhood?" Living with a parent or guardian who served time in jail or prison is based on responses by a knowledgeable adult, usually a parent, to the survey question, "Did (child) ever live with a parent or guardian who served time in jail or prison after (child) was born?" Estimates are based on household interviews of a sample of the civilian, noninstitutionalized U.S. population. Access data table for Figure 1 at: https://www.cdc.gov/nchs/data/ databriefs/db431-tables.pdf\#1.

SOURCE: National Center for Health Statistics, National Health Interview Survey, 2019

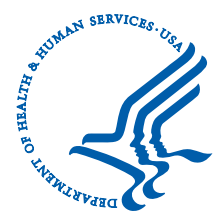




\section{NCHS Data Brief a No. 431 a January 2022}

- The percentage of children with disability who had been victims of or witnessed violence in their neighborhood (17.2\%) was more than three times higher than children without disability $(5.3 \%)$ (Figure 1).

- Among children with disability, $12.7 \%$ had experienced parental or guardian incarceration compared with $5.6 \%$ of children without disability.

\section{Children with disability were more likely to have ever lived with someone who was mentally ill or severely depressed or with someone with an alcohol or drug problem compared with their peers without disability.}

- Children with disability were more likely to have lived with someone who was mentally ill or had severe depression (21.6\%) compared with children without disability $(7.5 \%)$ (Figure 2).

- The percentage of children who had lived with someone with an alcohol or drug problem was higher among children with disability $(17.6 \%)$ than among children without disability $(8.6 \%)$.

Figure 2. Percentage of children aged 5-17 years who had lived with anyone with mental illness, or who had lived with anyone with an alcohol or drug problem, by disability status: United States, 2019

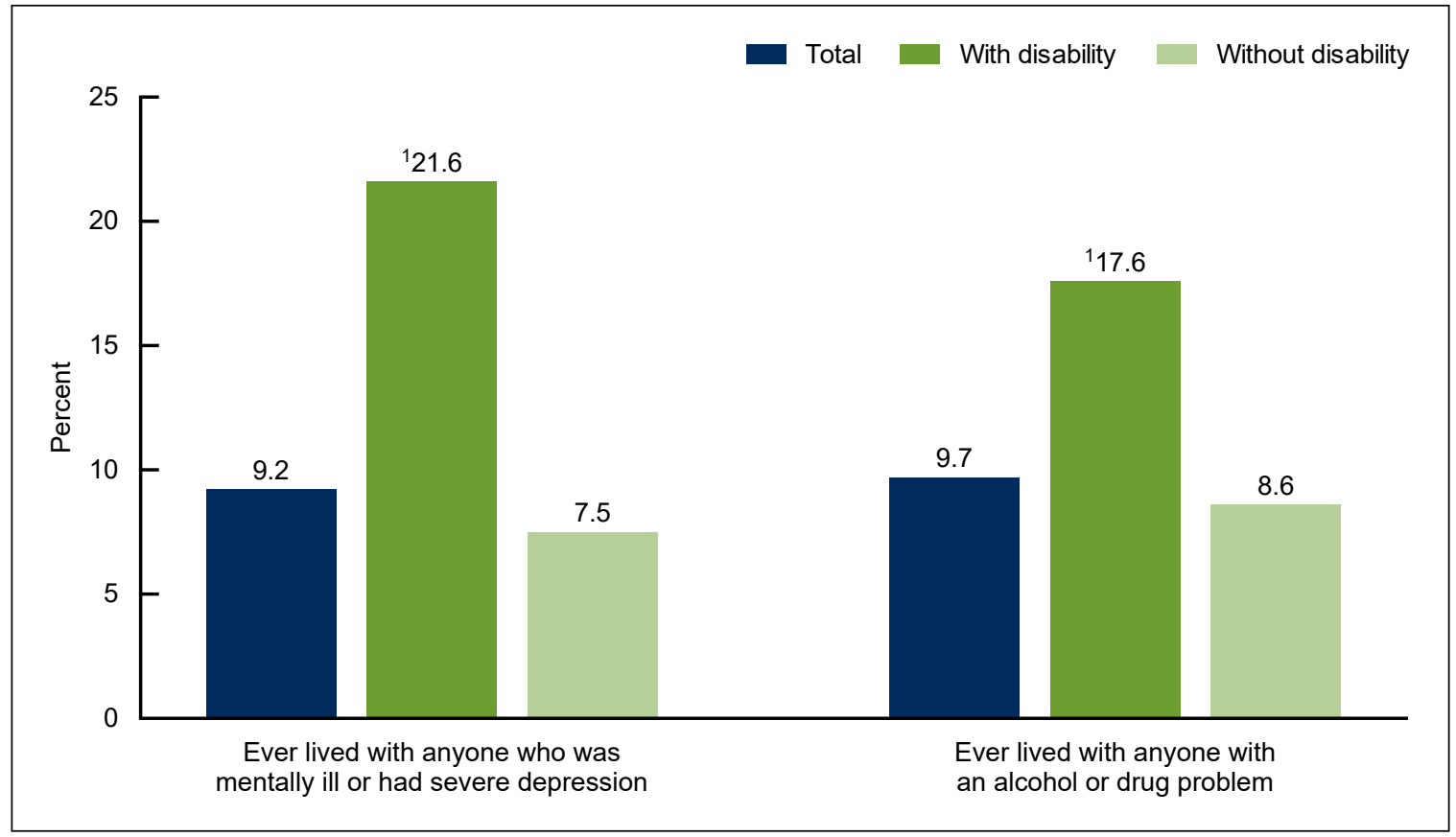

${ }^{1}$ Significantly different from children without disability $(p<0.05)$

NOTES: Ever lived with anyone who was mentally ill or severely depressed is based on responses by a knowledgeable adult, usually a parent, to the survey question, "Did (child) ever live with anyone who was mentally ill or severely depressed?" Ever lived with anyone who had a problem with alcohol or drugs is based on responses by a knowledgeable adult, usually a parent, to the survey question, "Did (child) ever live with anyone who had a problem with alcohol or drugs?" Estimates are based on household interviews of a sample of the civilian, noninstitutionalized U.S. population. Access data table for Figure 2 at: https://www.cdc.gov/nchs/data/databriefs/db431-tables.pdf\#2.

SOURCE: National Center for Health Statistics, National Health Interview Survey, 2019. 


\section{NCHS Data Brief a No. 431 a January 2022}

\section{Among children aged 5-17 years, 10.5\% had experienced one stressful life event, and $8.0 \%$ had experienced two or more.}

- The percentage of children aged 5-17 years who had not experienced any of the four stressful life events was lower among those with disability (64.1\%) than among those without disability (83.9\%) (Figure 3).

- Children with disability were more likely to experience one of the four stressful life events compared with their peers without disability (17.3\% versus $9.6 \%$, respectively).

- Children with disability were more likely to experience two or more of the four stressful life events $(18.6 \%)$ than those without disability $(6.5 \%)$.

Figure 3. Percentage of children aged 5-17 years who had experienced no, one, or two or more of four stressful life events, by disability status: United States, 2019

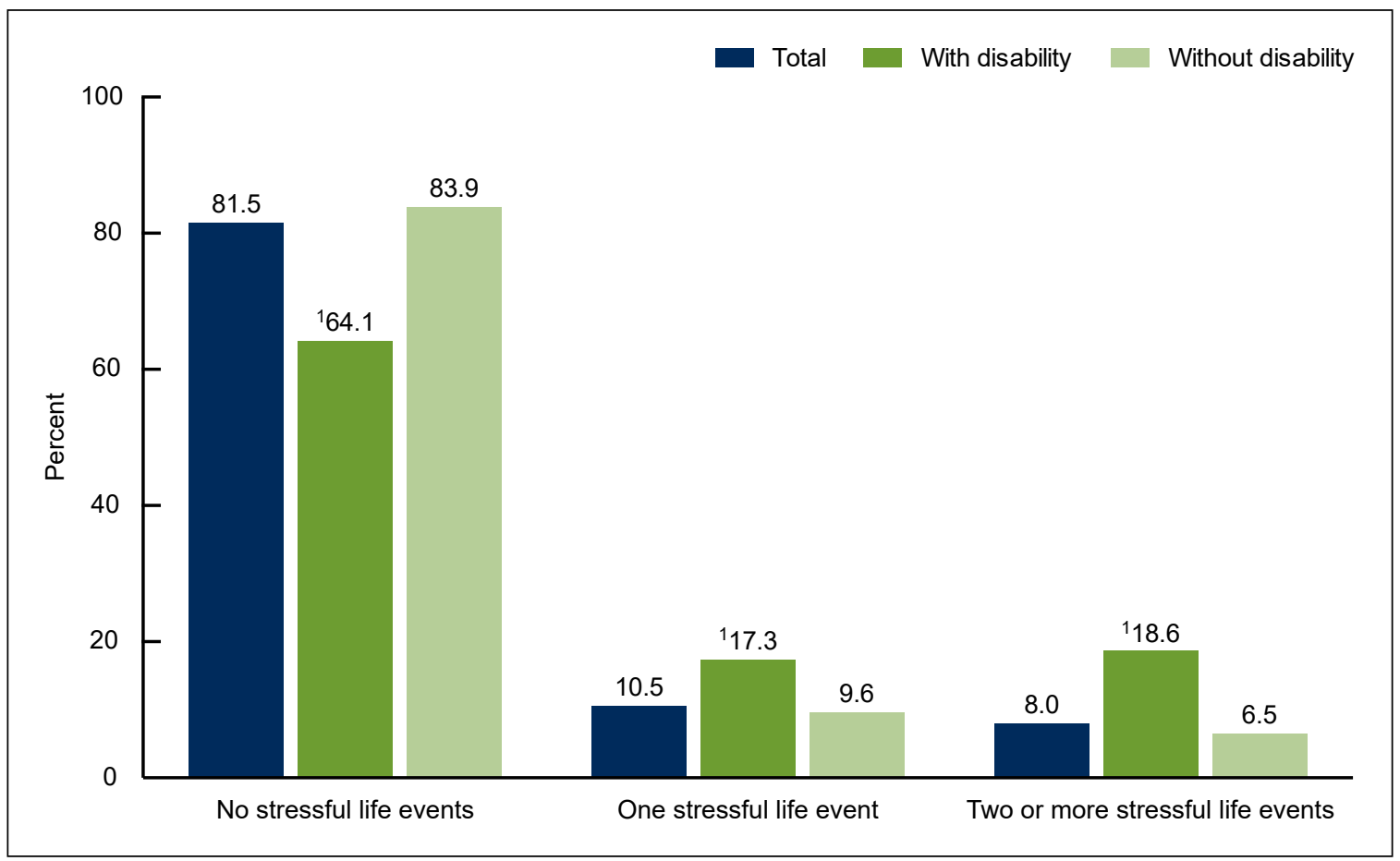

${ }^{1}$ Significantly different from children without disability $(p<0.05)$.

NOTES: Four stressful life events are considered: exposure to violence in the neighborhood, parental or guardian incarceration, ever having lived with anyone who was mentally ill or severely depressed, and ever having lived with anyone with an alcohol or drug problem. Estimates are based on household interviews of a sample of the civilian, noninstitutionalized U.S. population. Access data table for Figure 3 at: https://www.cdc.gov/nchs/data/databriefs/db431-tables.pdf\#3.

SOURCE: National Center for Health Statistics, National Health Interview Survey, 2019. 


\section{Summary}

Children with disability were more likely to have experienced each of the four stressful life events examined in this report compared with children without disability. The differences by disability status were especially pronounced for violence exposure in the neighborhood and having lived with someone who was mentally ill or severely depressed. While $17.2 \%$ of children with disability had been exposed to violence in their neighborhood, the corresponding figure for children without disability was 5.3\%. Among children with disability, $21.6 \%$ had lived with someone who was mentally ill or severely depressed, compared with $7.5 \%$ among those without disability. Moreover, disability status was associated with experiencing multiple stressful life events in children aged 5-17 years: $18.6 \%$ of children with disability had experienced two or more of the four stressful life events compared with $6.5 \%$ of children without disability. Experiencing multiple stressful life events in childhood is associated with a further increased risk for adverse health outcomes (13).

Although previous research has documented sociodemographic disparities in stressful life events among children aged 5-17 years (14), disability status is not often considered in this literature (2). Understanding patterns of adverse experiences among children with disabilities can inform policy to support these children and promote their health and full inclusion in society.

\section{Definitions}

Alcohol or drug problem: Children were categorized as having ever lived with someone with an alcohol or drug problem based on an affirmative response to the question, "Did (child) ever live with anyone who had a problem with alcohol or drugs?"

Disability status: Disability is defined by the reported level of difficulty (no difficulty, some difficulty, a lot of difficulty, or cannot do at all/unable to do) in 13 core functioning domains: seeing, hearing, mobility, self-care, communication, learning, remembering, concentrating, accepting change, controlling behavior, making friends, anxiety, and depression. Children who are reported to have "a lot of difficulty" or "cannot do at all" in at least one domain of functioning or with "daily" anxiety or depression are considered to have disability.

Mental illness: Children were categorized as having ever lived with someone who was mentally ill or severely depressed based on an affirmative response to the question, "Did (child) ever live with anyone who was mentally ill or severely depressed?"

Parental or guardian incarceration: Children were categorized as having a parent or guardian who served time in jail or prison based on an affirmative response to the question, "Did (child) ever live with a parent or guardian who served time in jail or prison after (child) was born?"

Violence exposure: Children were considered to have been exposed to violence in their neighborhood based on an affirmative response to the question, "Has (child) ever been the victim of violence or witnessed violence in his/her neighborhood?" 


\section{NCHS Data Brief $\square$ No. 431 January 2022}

\section{Data source and methods}

Data from the 2019 NHIS were used for this analysis. NHIS is a nationally representative household survey of the U.S. civilian noninstitutionalized population. It is conducted continuously throughout the year by the National Center for Health Statistics (NCHS). Interviews are conducted in respondents' homes, but follow-ups to complete interviews may be conducted over the telephone. Questions about the child's health are answered by a knowledgeable adult, usually a parent. Questions on stressful life events are only included periodically in NHIS. Stressful life events represent a subset of the Adverse Childhood Experiences (ACEs) that are frequently measured (15). For more information about NHIS, visit: https://www.cdc.gov/ nchs/nhis.htm.

Point estimates and corresponding confidence intervals for this analysis were calculated using Stata version 16 software (16) to account for the complex sample design of NHIS. Differences between percentages were evaluated using two-sided significance tests at the 0.05 level. All estimates meet NCHS standards of reliability as specified in "National Center for Health Statistics Data Presentation Standards for Proportions" (17).

\section{About the authors}

Heidi Ullmann and Julie D. Weeks are with the National Center for Health Statistics (NCHS), Division of Analysis and Epidemiology. Jennifer H. Madans is a guest researcher with NCHS, Office of the Director. 


\section{References}

1. Reichman NE, Corman H, Noonan K, Jiménez ME. Infant health and future childhood adversity. Matern Child Health J 22:318-26. 2018.

2. Berg KL, Shiu CS, Feinstein RT, Acharya K, MeDrano J, Msall ME. Children with developmental disabilities experience higher levels of adversity. Research in Developmental Disabilities 89:105-13. 2019.

3. Gilgoff R, Singh L, Koita K, Gentile B, Marques SS. Adverse childhood experiences, outcomes, and interventions. Pediatr Clin North Am 67(2):259-73. 2020.

4. Wright AW, Austin M, Booth C, Kliewer W. Systematic review: Exposure to community violence and physical health outcomes in youth. Journal of Pediatric Psychology 42(4):364-78. 2017.

5. Mohammad ET, Shapiro ER, Wainwright LD, Carter AS. Impacts of family and community violence exposure on child coping and mental health. J Abnorm Child Psychol 43:203-15. 2015.

6. Wildeman C, Goldman AW, Turney K. Parental incarceration and child health in the United States. Epidemiol Rev 40(1):146-56. 2018. DOI: 10.1093/epirev/mxx013.

7. Turney K, Haskins AR. Parental incarceration and children's well-being: Findings from the FFCW and Child Well-being Study. In: Eddy JM, Poehlmann-Tynan J, editors. Handbook on children with incarcerated parents. 2nd ed. Cham, Switzerland: 2019. Springer, 53-64.

8. Pierce M, Hope HF, Kolade A, Gellatly J, Osam CS, Perchard R, et al. Effects of parental mental illness on children's physical health: Systematic review and meta-analysis. Br J Psychiatry 217(1):354-63. 2020. DOI: 10.1192/bjp.2019.216.

9. Mowbray O, Jennings PF, Littleton T, Grinnell-Davis C, O'Shields J. Caregiver depression and trajectories of behavioral health among child welfare involved youth. Child Abuse Negl 79:445-53. 2018. DOI: 10.1016/j.chiabu.2018.03.001.

10. Kuppens S, Moore SC, Gross V, Lowthian E, Siddaway AP. The enduring effects of parental alcohol, tobacco, and drug use on child well-being: A multilevel meta-analysis. Dev Psychopathol 32(2):765-78. 2020. DOI: 10.1017/S0954579419000749.

11. Berg KL, Shiu CS, Feinstein RT, Msall ME, Acharya K. Adverse childhood experiences are associated with unmet healthcare needs among children with autism spectrum disorder. J Pediatr 202:258-64. 2018.

12. Marilyn M, Merrick MT, Klevens J, Ports KA, Ford DC. Adverse childhood experiences and life opportunities: Shifting the narrative. Children and Youth Services Review 72:141-9. 2017.

13. Hughes K, Bellis MA, Hardcastle KA, Sethi D, Butchart A, Mikton C, et al. The effect of multiple adverse childhood experiences on health: A systematic review and meta-analysis. Lancet Public Health 2:e356-66. 2017.

14. Ullmann H, Weeks JD, Madans JH. Disparities in stressful life events among children aged 5-17 years: United States, 2019. NCHS Data Brief, no 416. Hyattsville, MD: National Center for Health Statistics. 2021. DOI: https://dx.doi.org/10.15620/cdc:109052. 


\section{NCHS Data Brief a No. 431 a January 2022}

15. Felitti VJ, Anda RF, Nordenberg D, Edwards V, Koss MP, Marks JS. Relationship of childhood abuse and household dysfunction to many of the leading causes of death in adults: The Adverse Childhood Experiences (ACE) Study. AJPM 14(4):245-58. 1998.

16. StataCorp. Stata Statistical Software (Release 16) [computer software]. 2019.

17. Parker JD, Talih M, Malec DJ, Beresovsky V, Carroll M, Gonzalez JF Jr, et al. National Center for Health Statistics data presentation standards for proportions. National Center for Health Statistics. Vital Health Stat 2(175). 2017. 
Centers for Disease Control and Prevention

\section{NCHS Data Brief $n$ No. 431 a January 2022}

Keywords: functional limitations $\bullet$ violence $\bullet$ mental illness $\bullet$ drug or alcohol problem $\bullet$ National Health Interview Survey (NHIS)

\section{Suggested citation}

Ullmann H, Weeks JD, Madans JH. Stressful life events among children aged 5-17 years by disability status: United States, 2019. NCHS Data Brief, no 431. Hyattsville, MD: National Center for Health Statistics. 2022. DOI:

https://dx.doi.org/10.15620/cdc:112970.

\section{Copyright information}

All material appearing in this report is in the public domain and may be reproduced or copied without permission; citation as to source, however, is appreciated.

\section{National Center for Health Statistics}

Brian C. Moyer, Ph.D., Director Amy M. Branum, Ph.D., Associate Director for Science

Division of Analysis and Epidemiology Irma E. Arispe, Ph.D., Director Kevin C. Heslin, Ph.D., Associate Director for Science

For e-mail updates on NCHS publication releases, subscribe online at: https://www.cdc.gov/nchs/email-updates.htm.

For questions or general information about NCHS:

Tel: 1-800-CDC-INFO (1-800-232-4636)

TTY: 1-888-232-6348

Internet: https://www.cdc.gov/nchs

Online request form: https://www.cdc.gov/info

ISSN 1941-4927 Print ed.

ISSN 1941-4935 Online ed. 